\title{
The association between South African investors' financial risk tolerance and demographic variables
}

\section{Authors:}

Leandri Maritz ${ }^{1}$ (D)

Merwe Oberholzer ${ }^{2}$ (D)

\section{Affiliations:}

${ }^{1}$ School of Accounting Sciences, Faculty of Economic and Management Sciences, North-West University, Potchefstroom, South Africa

${ }^{2}$ WorkWell Research Unit, Faculty of Economic and Management Sciences, North-West University, Potchefstroom, South Africa

\section{Corresponding author:} Merwe Oberholzer, merwe.oberholzer@nwu.ac.za

\section{Dates:}

Received: 26 Mar. 2019 Accepted: 02 Aug. 2019 Published: 29 Oct. 2019

How to cite this article: Maritz, L. \& Oberholzer, M. 2019, 'The association between South African investors' financial risk tolerance and demographic variables', Journal of Economic and Financial Sciences 12(1), a469. https://doi.org/ 10.4102/jef.v12i1.469

\section{Copyright:}

C 2019. The Authors. Licensee: AOSIS. This work is licensed under the Creative Commons Attribution License.

\section{Read online:}

Scan this QR code with your smart phone or mobile device to read online.
Orientation: The expected utility theory was used as the lens to focus on how South African investors' demographics are associated with their financial risk tolerance.

Research purpose: To determine the association between eight demographic variables of investors and their financial risk tolerance scores.

Motivation for the study: Instead of applying a single aggregated risk tolerance score, this study distinguishes itself from most other studies to refine risk tolerance into various factors.

Research approach/design and method: Data for this study were obtained from FinaMetrica Pty Ltd, namely the results of their 25-item risk tolerance questionnaire, which also includes eight demographic variables of the respondents. In total, 3473 of the respondents were considered valuable. This study identified three risk tolerance factors: factor 1 (level of risk), factor 2 (past experience) and factor 3 (personal feelings and attitudes).

Main findings: The study found that men are statistically significantly more risk tolerant than women, and investors' education level, income level and combined income are all positively statistically significantly associated with risk tolerance as per factors 1, 2 and 3. Some unique findings were revealed from this study, that is, as investors age, their risk tolerance increases (as per factor 1); married investors are more risk tolerant than the unmarried (as per factor 2); and the number of dependents is positively associated with risk tolerance, factors 1 and 2 .

Practical/managerial implications: The practical value of the study is that investors and financial advisors have a more enhanced view to better understand the degree of association of demographic variables on investors' level of risk; the roles of past experiences and personal attitudes and feelings are associated with demographic variables.

Contribution/value-add: Breaking up the risk tolerance into factors contributes to a more refined analysis being conducted.

Keywords: financial risk tolerance; demographic variables; South African investors; finametrica; expected utility.

\section{Introduction}

Financial risk tolerance is seen as an aspect of utility for any investment decision; therefore, it should be measured because the ultimate goal of any financial activity is the maximisation of the expected utility (Sulaiman 2012:109). Financial risk tolerance can be described as the maximum amount of uncertainty that individuals are prepared to accept when making financial decisions (Chavali \& Mohanraj 2016:169), or the degree to which investors are willing to accept a less favourable outcome in pursuit of one that is more favourable (FinaMetrica 2015). Financial risk tolerance is the most important factor that is used to determine the composition of asset portfolios for investors and demands to align with the terms of risks and returns that meet the needs of these investors (Ho, Milevsky \& Robinson 1994:111).

In this study, the expected utility theory was used as the lens to focus on how South African investors' demographic (including socio-economic) variables are associated with their expected utility, as measured by their risk tolerance scores. According to Davis, Hands and Maki (1997), the expected utility theory states that investors or decision-makers have to choose between risky or uncertain investment opportunities or prospects by comparing their expected utility values. Kahneman and Tversky (1979) are of the opinion that the expected utility theory is dominating the analysis of decision-making under risk. A review of current risk-taking and risk-tolerance research indicates that various variables, such as gender, age, education, income, dependents, marital status and wealth (Chavali \& Mohanraj 2016; Hallahan, Faff \& McKenzie 2004; Kuzníak 
et al. 2015; Roszkowski \& Grable 2005) can influence the level of risk-taking in everyday investing decisions and matters (Grable 2000:626).

The risk tolerance and demographic variables were investigated within a South African context. Therefore, the importance, or significance, of considering demographics to determine the risk objectives of investors was studied within an emerging market context, such as South Africa, where the diversity concerning demographics is unique compared to other regions around the world. Limited similar research has been conducted in this region, that is, the studies by Metherell (2011) and Mabalane (2015) who analysed the association between risk tolerance and demographic variables of South African investors. Metherell (2011) analysed a sample of South Africans by applying the Grable-Lytton questionnaire, while Mabalane's (2015) study, which is more related to our study, analysed FinaMetrica data and compared the results of investors of different cultures, that is, South Africa, Australia, the United Kingdom and the United States. However, our study is a refinement of the above-mentioned works by breaking the single aggregated financial risk tolerance score into smaller factors.

Grable, McGill and Britt (2009) indicate that to measure the financial risk tolerance of investors is difficult because there are various dimensions involved. One of the issues is that there is no universal or standardised method to determine an individual's risk tolerance. Heo, Grable and Rabbani (2018) mention that the two popular widely used psychometrically developed scales are the 13-item questionnaire of Grable and Lytton (2003) and the 25-item questionnaire of FinaMetrica. There are many others, for example the 93-item questionnaire used by Roszkowski and Grable (2005) and the 85-item questionnaire used by Holzhauer et al. (2016). Yook and Everett (2003) found a low correlation between six questionnaires analysed in their article: 'Assessing Risk Tolerance: Questioning the Questionnaire Method'. Obviously, different questionnaires will provide different results. Data for this study were obtained from FinaMetrica Pty Ltd, namely the results of their 25-item risk tolerance questionnaire, which also includes eight demographic variables of the respondents. The motivation for this choice is that the FinaMetrica risk tolerance profile meets or exceeds international standards for assessments of its kind with a reliability of 0.9 out of 1' (Finametrica 2019). Other studies that used FinaMetrica's questionnaire or data are, inter alia, Hallahan et al. (2004), Moreschi (2005), Faff, Hallahan and McKenzie (2009), Van de Venter, Michayluk and Davey (2012), Sulaiman (2012), Mabalane (2015) and Grable, Heo and Kruger (2016).

The ability of investors to handle risk can be related to demographic variables (Chavali \& Mohanraj 2016:169). The latter can be used by investors to distinguish between the levels of financial risk tolerance. A link between these factors can be established to help and predict the risk tolerance of investors (Grable 2000:625). The eight demographic variables from the FinaMetrica database are gender, age, education level, income (and combined) level, marital status, number of dependents and value of assets, which is a proxy for wealth. These demographic variables are similar to those used in other studies - which did not use the FinaMetrica questionnaire - to determine their association with risk tolerance. These studies are, for example, Roszkowski and Grable (2005), Grable et al. (2009), Yoa, Sharpe and Wang (2011), Gilliam and Chatterjee (2011), Metherell (2011), Pan and Statman (2012), Lucarelli, Uberti and Brigetti (2015), Kuzníak et al. (2015), Chavali and Mohanraj (2016) and Heo et al. (2018).

Following the above-mentioned studies, the main objective of the study was to determine the association between the eight demographic variables of investors and their financial risk tolerance. The database acquired from FinaMetrica contains over 370000 financial risk evaluations. It has been filtered so that there are only South African investors left whose data were fully complete with no missing values. The aim of the research was to better understand how South African investors make financial decisions, and whether the identified demographic variables have an effect on financial risk tolerance within a South African context.

The motivation to do the investigation within a South African context is that it can contribute to the literature because limited research has been conducted previously in this area. Only the two mentioned published studies, with some contradictory findings, Metherell (2011) and Mabalane (2015), were detected that also investigated the association between South African investors' risk tolerance and demographic variables. Furthermore, instead of applying a single aggregated risk tolerance which was practised in the above-mentioned list of similar studies (except for Holzhauer et al. 2016), a secondary objective of this study was to distinct itself to refine the 25-item risk tolerance questionnaire into factors, after which the association between the risk tolerance factors and the demographic variables was analysed. Therefore, the contribution to the literature is that this study is a refinement of these kind of association studies. Consequently, an exploratory factor analysis was conducted to factorise these items and to calculate a risk tolerance score for each factor instead of using a single score for the all items. Limited research has been conducted to factorise risk tolerance questionnaires. A related study was conducted by Holzhauer et al. (2016), who analysed a self-developed 85 -item risk tolerance questionnaire based on four factors identified by Cordell (2001), that is, risk attitude, risk propensity, risk knowledge and risk capacity. They also added another factor, namely risk personality.

The next section is the literature review to provide some insight to interpret and learn from the results of related empirical studies. This is followed by a section that explains the research methodology and design. Thereafter, the results of the empirical study are presented and discussed, after which the study is concluded. 


\section{Literature}

This section summarises related literature on how demographic characteristics of investors are associated with their financial risk tolerance. However, with this kind of quantitative research, this is not unusual that researchers do not necessarily agree with each other's findings and mixed results were frequently noticed as already indicated by, inter alia, Moreschi (2005), Sulaiman (2012) and Mabalane (2015). Therefore, the aim of this section is to introduce the reader to general beliefs of practitioners and researchers.

\section{Gender}

There is a persistent belief that men are more risk tolerant than women are (Sulaiman 2012:110). Bajtelsmit and Bernasek (1996:1) asked the following question: 'Why do women invest differently than men?' They investigated this phenomenon and found that women have a lower risk tolerance, which causes them to have lower returns than men in the long run. This finding was contradictory to their theory because women were found to have a longer life expectancy than men (Ho et al. 1994:110), which makes women more ideal to invest in a riskier portfolio. The gap between the investment portfolios of men and women is of enormous economic importance (Bannier \& Neubert 2016:130). If women are less willing to invest in risky financial assets, it is expected of them to earn less money and have lower returns over time (Ryack \& Sheikh 2016:157). Because women are expected to have a longer lifespan, and they have a lower labour income and are more risk averse, women are more vulnerable to experience poverty in old age (Bannier \& Neubert 2016:130).

\section{Age and generation}

A general perception is that risk tolerance decreases with age. Yoa et al. (2011:880) and Sulaiman (2012:110) highlight that risk tolerance relates negatively to age. Grable et al. (2009:9) established that older working adults are more prone to underrate their risk tolerance than younger working adults. Despite all the research conducted regarding the age effect on financial risk tolerance, no clear conclusion can be drawn concerning the strengths of this relationship. Most of the research indicates that risk tolerance decreases with age (Metherell 2011; Yoa et al. 2011:880) and that an inverse relationship exists between risk tolerance and financial decisions of individuals (Kannadhasan 2015:177).

The age and generation variables are very closely related, but they may show different outcomes. In short, as individuals age, the way in which they make financial decisions may change. The generation variable is based on the assumption that the timeframe in which individuals were born will affect their behaviour because of the way the world is changing and what is happening in the world around them. Therefore, the timeframe in which individuals were born will affect their financial decisions. Each generation experiences a distinctive demographic, political and socio-economic environment and the experiences shared by a generation can affect their attitude towards financial risk (Russo \& Schoemaker 1992:16). Contrasting experiences shared by generations may contribute to dissimilar attitudes towards financial risks. For example, investors who experienced the Great Depression tended to remain risk averse for the remainder of their lives (Grable 2013:8).

\section{Education}

The level of education of investors has an effect on the risk that investors are willing to take. Yoa et al. (2011:885), Faff et al. (2009:1330), Grable et al. (2009:5) and Sulaiman (2012:113) found that education also has a positive effect on the willingness of respondents to take more financial risks. Investors with a higher education level tend to be more willing to take on financial risks as they know how to evaluate investment options. They also have strategies in place when losses occur on how to recover from them. Less educated investors tend to be more risk averse and they do not want to suffer financial losses as the recovery period tends to be longer (DeHart et al. 2016:3).

\section{Income, combined income and wealth}

The income, combined income and wealth variables may be related and are discussed together. Income, combined income, also referred to as total household income, and total asset value, a proxy for wealth, are generally regarded in the literature to be positively related to risk tolerance (Hallahan et al. 2004:167; Mabalane 2015:113; Metherell 2011:142; Sulaiman 2012:113).

One of the biggest impacts of income and wealth on financial risk tolerance is how quickly investors can recover if major financial losses are suffered. The study of Abhijeet and Dinesh (2010:10) predicted that the income of investors can have an effect on the amount of risk investors are willing to shoulder. The overall objective of financial investments is to obtain good returns (Chavali \& Mohanraj 2016:169), but at a risk level they could recover from quickly should losses occur.

\section{Marital status and household size}

Marital status and household size may be somewhat related as married couples probably may have more dependents in their household than non-married persons. Nevertheless, authors such as Faff et al. (2009:1330), Sulaiman (2012:113-114) and Grable et al. (2016:48) found that married persons are less risk tolerant than unmarried persons, and that as the number of dependents increases in a household, the lower the respondents' risk tolerance will be. The logic for this phenomenon is that married people have a responsibility towards their spouse and become more risk adverse than unmarried people. Similarly, as the number of dependents grows, individuals' responsibility increases and they will act more risk averse. 


\section{Research methodology and design Methodology and data source}

In 1997, FinaMetrica Pty Ltd (formerly ProQuest and currently part of PlanPlus Global), an Australian-based riskprofiling firm, developed a valid and reliable 25-question psychometric risk assessment test together with the Applied Psychology Unit of the University of New South Wales School of Psychology. Since 1998, FinaMetrica has used its online risk profiling system (and hard copy questionnaires) to obtain information of investors and now they have a database with more than a million risk profiles of investors worldwide. The data were made available during 2017 for this study by FinaMetrica and included a subset of 370000 profiles of which 4979 are South African investors who completed the questionnaire. Only investors who were between the ages of 21 and 65 years when they completed the questionnaire were included in the population because it was assumed that those younger than the former are still studying and those older than the latter retired, respectively. After the data were filtered, 3473 of the respondents were considered valuable as all the desired information was obtained.

In this research study, the answers to the risk assessment questions in the questionnaire were used to categorise the risk tolerance of investors by allocating a score (between 0 and 100) to each of the investors; 0 represents a complete riskavoidance attitude and 100 represents a risk-seeking attitude.

The data were analysed by applying the following statistical techniques: (1) descriptive statistics to explain the data; (2) corrected item-total correlation, exploratory factor analysis and communality estimate to analyse the risk assessment questionnaire; and (3) ANOVA, correlation analysis and multi-regression analysis to test the association between risk tolerance and demographic variables. For the regression model, the financial risk tolerance served as the dependent variable and each of the eight demographic variables served alternatively as the independent variables with the remaining variables as mediators.

The age of investors may have an effect on the financial risk tolerance scores and was used in the correlation analysis. For the multiple regression analysis, three generation groups replaced age for a more detailed explanation. The following generation groups were identified and incorporated (Serafino 2018): Baby Boomers: 1946-1964; Generation X: 1965-1980 and Millennials: 1981-1995.

Finally, the analysis of the data was also tested for reliability by determining the Cronbach's alpha, a measurement tool of internal consistency, which was 0.899 . It is very close to 1 , indicating that the data used in this research study were reliable (Field 2009:681).

\section{Descriptive statistics of demographic variables}

Table 1 exhibits the descriptive statistics of the demographic variables data. The data are categorical in nature, except 'age'
TABLE 1: Descriptive statistics of demographic variables.

\begin{tabular}{lcccccc}
\hline Variable & $\boldsymbol{N}$ & Mean & $\begin{array}{l}\text { Standard } \\
\text { deviation }\end{array}$ & Median & Minimum & Maximum \\
\hline Gender & 3473 & 1.428 & 0.495 & 1 & 1 & 2 \\
Age (year of birth) & 3473 & 1970 & 10.641 & 1966 & 1933 & 1996 \\
Baby Boomers & 1359 & 1955 & 0.498 & 1956 & 1946 & 1964 \\
Generation X & 1111 & 1973 & 0.428 & 1973 & 1965 & 1980 \\
Millennials & 720 & 1988 & 0.450 & 1985 & 1981 & 1995 \\
Education & 3473 & 3.387 & 0.798 & 4 & 1 & 4 \\
Income & 3473 & 3.360 & 1.303 & 3 & 1 & 6 \\
Marital status & 3473 & 1.293 & 0.455 & 1 & 1 & 2 \\
Combined income & 2657 & 3.945 & 1.222 & 4 & 1 & 6 \\
Number of dependents & 3473 & 1.565 & 1.473 & 1 & 0 & 10 \\
Value of net assets & 3473 & 6.129 & 2.318 & 6 & 1 & 10 \\
\hline
\end{tabular}

and 'number of dependents', where an exact number could be applied. For example, if a respondent selects the year of birth and the year of completion of the questionnaire is available, the exact age of the person can be determined. For the number of dependents, the respondents can also provide the exact number.

Note that age (year of birth) had a minimum of 1933 and a maximum of 1996. This indicates that the data captured in the FinaMetrica database consisted of the information of individuals born in these years. Because the data were captured over a time period, the individual born in 1933 could have already passed away. The median of age and the different generations included in Table 1 only indicated what year the middle value of age or of that generation was born. The three generations were classified as categorical data, which were treated as a dummy variable in the regression model, where a ' 1 ', ' 2 ' or ' 3 ' could be attached to each respondent.

Gender, also a dummy variable, has a minimum of 1 and a maximum of 2 . This is because of males being given a numerical value of 1 and females a value of 2 . The median was 1 because of most of the investors being male, the median lies within males. For the variables education level, income level, combined income and value of net assets, the respondents may choose among 4,6 and 10 value categories, which range from low to high. For marital status, a ' 1 ' or a ' 2 ' is attached to a married and unmarried person, respectively (see Appendix 1 for a more detailed exhibition).

\section{Hypothesis}

To assist in reaching the main objective of the study, the following null and alternative hypotheses were developed to test the association between risk tolerance and the demographic variables:

$H_{0}$ (1): $\beta_{1}=0$ (There is no significant relationship between financial risk tolerance and alternatively gender, age or generation, education, income, combined income, marital status, dependents and total assets).

$H_{1}(1): \beta_{1} \neq 0$ (There is a significant relationship between financial risk tolerance and alternatively gender, age or generation, education, income, combined income, marital status, dependents and total assets). 


\section{Ethical considerations}

Ethical clearance was obtained from the North-West University (NWU-00439-18-S4).

\section{Results}

\section{Analysis of the FinaMetrica questionnaire}

The secondary objective was to refine the 25 investors' financial risk tolerance (RT) items or questions of the FinaMetrica's questionnaire. (Note that we further on use the abbreviations RT1 to RT25 to refer to these questions.) This study followed, inter alia, Moreschi (2005) and Paradi, Sherman and Tam (2018), who only used the first 24 of the 25-item questionnaire to calculate investors' risk tolerance because the last question is the individual investors' perception of their own risk tolerance score.

The questions are exhibited in Appendix 2 (also available on FinaMetrica's website) of which investors choose an appropriate answer from a list of possible answers. The answers can be 'Yes' or 'No', or they are provided with a list with more detailed options to choose from. Investors choose the option that explains them the best and their answers are used to determine a financial risk tolerance score.

\section{Corrected item-total correlation}

A corrected item-total correlation was the first tool used to analyse the first 24 items listed in the questionnaire, which tested for correlations between the different questions. The higher the correlation, the higher that specific question was related to the rest of the questions, and vice versa (Flom 2018).

Based on the correlations listed in Table 2, it is evident that the first six questions have the highest correlation with the other questions. These six questions were, therefore, viewed as the most important questions that assisted in determining the financial risk tolerance scores of investors. The higher the correlation, the higher the impact of that question will be. The first six questions had a correlation of approximately 0.6 or higher. These six questions include RT16 - what type

TABLE 2: Corrected item-total correlation (from the highest to the lowest correlation).

\begin{tabular}{lccccc}
\hline Ranking & Question & $\begin{array}{c}\text { Corrected item- } \\
\text { total correlation }\end{array}$ & Ranking & Question & $\begin{array}{c}\text { Corrected item- } \\
\text { total correlation }\end{array}$ \\
\hline 1 & RT16 & $0.733 \dagger$ & 13 & RT6 & 0.523 \\
2 & RT10 & $0.707 \dagger$ & 14 & RT13 & 0.518 \\
3 & RT1 & $0.704 \dagger$ & 15 & RT2 & 0.495 \\
4 & RT20 & $0.664 \dagger$ & 16 & RT22 & 0.476 \\
5 & RT9 & $0.598 \dagger$ & 17 & RT12 & 0.468 \\
6 & RT19 & $0.596 \dagger$ & 18 & RT18 & 0.435 \\
7 & RT14 & 0.585 & 19 & RT4 & 0.416 \\
8 & RT17 & 0.580 & 20 & RT7 & 0.393 \\
9 & RT3 & 0.542 & 21 & RT11 & 0.301 \\
10 & RT21 & 0.540 & 22 & TR15 & 0.300 \\
11 & RT8 & 0.539 & 23 & RT23 & -0.264 \\
12 & RT5 & 0.535 & 24 & RT24 & 0.125 \\
\hline
\end{tabular}

$\dagger$, Correlation close to or more than 0.6 . of investment do investors find the most appealing; RT10 - the degree of risk investors are currently prepared to take; RT1 - how investors rate their willingness to take financial risks; RT20 - the willingness of investors to invest in certain types of funds; RT9 - past financial risks taken by investors and RT19 - how the personal investments of investors have changed over the years.

The following two questions had the lowest correlation and did not provide values that aligned with the values and information obtained from the other questions: RT23 - how the loans of investors should be made up and RT24 - how much insurance cover investors have. It was, therefore, decided to not use these two questions in the analyses because these questions did not assist in the accuracy and validity of the study.

\section{Exploratory factor analysis}

An exploratory factor analysis was performed to group the questions asked in the questionnaire into smaller groups that relate to each other (Pietersen \& Maree 2016:244). The questions asked in FinaMetrica's questionnaire were analysed according to their initial Eigenvalues and groups of questions with the highest significance were identified. If the Eigenvalue is more than 1, it confirms the factor is of significance (Pietersen \& Maree 2016:243). The data were grouped where the values attached to the questions fitted the best and related questions were then paired. The researchers only included questions into a group where the variance was more than or very close to 0.5 to ensure that only closely related questions were grouped together (Costello \& Osborne 2005). After the factors were identified, the next step was to determine each factor's internal reliability, where accepted values are more than 0.7 (Field 2009:681).

Table 3 shows the three major factors that were extracted from the questions in the questionnaire.

The results of the top three identified factors were inserted, as all of the questions were initially relevant; however, only 16 questions were included after the cut-off, where factor loadings of less than 0.5 were eliminated. Factor 1 initially consisted of 18 questions of which 10 questions were significant. Factor 2 initially consisted of seven questions, of which four questions were significant, while factor 3 initially consisted of seven questions, of which only two were significant. It can be inferred from Table 3 that factor 1 is dominant relative to factors 2 and 3 , and consists of $33.18 \%$ of the questions in the questionnaire that were used to group and calculate the financial risk tolerance scores of investors. The Cronbach's alpha shows that factor 1's internal reliability is excellent with a score of more than 0.8 , and factor 2 is good with a score of 0.695 , which is almost at the acceptable level of 0.7 . Only factor 3 , with a score of 0.634 , is a bit questionable as to whether the two items really belong together.

From the questions that were grouped together with the aid of a factor analysis, each group was titled based on the 


\begin{tabular}{|c|c|c|c|c|}
\hline \multirow[t]{2}{*}{ No. } & \multirow[t]{2}{*}{ Description } & \multicolumn{3}{|c|}{ Factor loadings } \\
\hline & & F1 & F2 & F3 \\
\hline \multicolumn{5}{|c|}{ Factor 1: Level of risk } \\
\hline RT16 & $\begin{array}{l}\text { Which mix of investments do you find most appealing? Would you prefer all low-risk/ low-return, all high-risk/ high-return, } \\
\text { or somewhere in between? }\end{array}$ & 0.739 & - & - \\
\hline RT20 & $\begin{array}{l}\text { How much of the funds you have available to invest would you be willing to place in investments where both return and risk are } \\
\text { expected to be above average? }\end{array}$ & 0.728 & - & - \\
\hline RT10 & What degree of risk are you currently prepared to take with your financial decision? & 0.694 & - & - \\
\hline RT14 & By how much could the total value of all your investments go down before you would begin to feel uncomfortable? & 0.633 & - & - \\
\hline RT21 & $\begin{array}{l}\text { Think of the average rate of return you would expect to earn on an investment portfolio over the next } 10 \text { years. How does this compare } \\
\text { with what you think you would earn if you invested the money in 1-year CDs (certificates of deposit)? }\end{array}$ & 0.616 & - & - \\
\hline RT19 & In recent years, how have your personal investments changed? & 0.604 & - & - \\
\hline RT1 & You have to rate your willingness to take financial risk. & 0.550 & - & - \\
\hline RT22 & Would you take a risk in arranging your affairs to qualify for a government benefit or obtain a tax advantage? & 0.531 & - & - \\
\hline RT13 & If you had a bad past experience with a company, would you buy stock now if the company is under new management? & 0.510 & - & - \\
\hline RT4 & Have you ever invested a large sum in a risky investment mainly for the 'thrill' of seeing whether it went up or down in value? & - & 0.689 & - \\
\hline RT11 & Have you ever borrowed money to make an investment (other than for a home)? & - & 0.686 & - \\
\hline RT9 & What degree of risk would you have taken with your financial decisions in the past? & - & 0.544 & - \\
\hline RT8 & If you were in a job where you could choose to be paid a salary, commission or a mix of both. What would you pick? & - & 0.525 & - \\
\hline \multicolumn{5}{|c|}{ Factor 3: Personal feelings and attitude } \\
\hline RT7 & How do you feel about financial decisions after making them? & - & - & 0.793 \\
\hline RT12 & How much confidence do you have in your abilities to make good financial decisions? & - & - & 0.613 \\
\hline \multicolumn{2}{|c|}{ Eigenvalue } & 7.963 & 1.186 & 1.142 \\
\hline \multicolumn{2}{|c|}{ Percentage of data explained } & 33.18 & 4.94 & 4.76 \\
\hline \multicolumn{2}{|c|}{ Cumulative variance explained } & 33.18 & 38.12 & 42.88 \\
\hline \multicolumn{2}{|c|}{ Cronbach's alpha } & 0.862 & 0.695 & 0.634 \\
\hline
\end{tabular}

questions that were grouped together. Factor 1 was called level of risk: this group consisted of underlying questions focusing on the risk appetite of investors and how their appetite has changed over recent years. Factor 2 was called past experience: this group consisted of underlying questions focusing on the financial decisions that were made by investors in the past and how they handled certain situations. Finally, factor 3 was called personal attitudes and feelings: this group consisted of underlying questions focusing on the concern of investors when financial decisions are made and how they feel when something goes wrong.

\section{Communality estimates of risk tolerance questions}

It is clear from the previous section that factor 1 (level of risk) contained the largest number of questions and the underlying question focuses on the risk appetite of investors and how their appetite has changed over recent years. A large number of questions were grouped together and they were not evenly spread and additional calculations are, therefore, necessary to determine the importance of these questions with regard to the financial risk tolerance scores of the investors.

A communality estimate was done where the variance between each question and the financial risk tolerance scores was tested. Communality estimates are the proportion of variance of the variables accounted for by the common factors and may range between 0 and 1 (Field 2009:647). It is calculated by adding the sum of squares of each row of the factor pattern matrix. A higher communality estimate is therefore better. The results are shown in Table 4, where communalities of higher than 0.5 , the acceptable values, are indicated (Field 2009).
From the communality estimate listed in Table 4 , it is clear which of the questions have the closest variance to the financial risk tolerance scores. The highest influencing questions were RT16 and RT7, with variances of 0.646 and 0.645 , respectively. RT16 focused on the preference of investors with regard to their financial risk tolerance levels, and the focal point of RT7 was the feelings of investors after making certain financial decisions. The next questions were RT10 (degree of risk investors are prepared to take), RT20 (change in the total level of investments before investors get uncomfortable), RT1 (rate your risk), RT9 (feelings about financial decisions) and RT4 (adventure of risk-taking). These identified questions had a high relationship and assisted in determining the financial risk tolerance scores of investors more accurately.

\section{Association between demographic variables and risk tolerance}

The main objective was to analyse the association between the available demographic variables of investors and their financial risk tolerance. Therefore, an ANOVA, correlation analysis and multiple regression analysis were applied.

\section{Analysis of variance}

To obtain an overall broad picture, the financial risk tolerance score of each of the investors was calculated to determine the correlation between the investors' demographics and their total financial risk tolerance score. Eta-squared $\left(\eta^{2}\right)$ measures the effect size in ANOVA. $\eta^{2}$ is calculated as follows: the sum of squares of the complete group divided by the sum of squares of the total. Eta-squared can be interpreted as follows: 
TABLE 4: Communality estimate of the risk tolerance questions.

\begin{tabular}{lccccc}
\hline Ranking & Question & Communality & Ranking & Question & Communality \\
\hline 1 & RT16 & $0.646 \dagger$ & 12 & RT19 & 0.447 \\
2 & RT7 & $0.645 \dagger$ & 13 & RT8 & 0.444 \\
3 & RT10 & $0.603 \dagger$ & 14 & RT21 & 0.425 \\
4 & RT20 & $0.591 \dagger$ & 15 & RT5 & 0.407 \\
5 & RT1 & $0.590 \dagger$ & 16 & RT6 & 0.389 \\
6 & RT9 & $0.526 \dagger$ & 17 & RT3 & 0.380 \\
7 & RT4 & $0.518 \dagger$ & 18 & RT2 & 0.365 \\
8 & RT12 & 0.476 & 19 & RT13 & 0.343 \\
9 & RT11 & 0.472 & 20 & RT22 & 0.319 \\
10 & RT17 & 0.463 & 21 & RT18 & 0.306 \\
11 & RT14 & 0.461 & 22 & RT15 & 0.275 \\
\hline
\end{tabular}

$\dagger$, Communality estimate more than 0.5 .

0.01 is a small correlation; 0.06 is a moderate correlation and 0.14 is a large correlation (Gujarati \& Porter 2010:179). An etasquared analysis was done on the FinaMetrica data, which resulted in $\eta^{2}=0.0719$. From this score obtained, a moderate correlation was determined between the total financial risk tolerance scores of the investors and their demographic variables.

\section{Correlation analysis between demographic variables and risk tolerance}

A Pearson correlation was performed between each demographic variable and the risk tolerance score according to each of the three factors. If the $p$-value was less than $1 \%$ and $5 \%$, the $H_{0}$ was rejected because of overwhelming and strong evidence, respectively (Wegner 2007:266-267). The data shown in Table 5 confirm the analysis done between the different demographic variables and factor 1 (level of risk), factor 2 (past experience) and factor 3 (personal attitudes and feelings).

Factor 1: In Table 5, it is evident that, with regard to gender, age, education level, income, annual combined income and number of dependents, the $p$-values were below $1 \%$, and overwhelming evidence was found to reject the null hypothesis, implying there is a statistically significant relationship between the mentioned demographic variables and risk tolerance as per factor 1, which presents their risk level. Gender showed a negative correlation, indicating that there is a negative relationship between gender and financial risk tolerance. Male investors were given a numerical value of 1 and females a numerical value of 2 . A negative relationship indicates that if an investor is female, there will be a negative relationship, indicating that females will take a lower risk tolerance than males. From the other positive significant relationships, it is evident that the higher the investors' age, education level, income, combined income and number of dependents, the more they are willing to tolerate a higher level of risk.

Factor 2: With regard to all the demographic variables, except for age, the $p$-values were close to or below $1 \%$, which is overwhelming evidence to reject the null hypothesis, implying there is a statistically significant relationship between the mentioned demographic variables and risk tolerance, as per factor 2, which presented their past experience. The positive
TABLE 5: Correlation between factors' risk tolerance scores and demographic variables.

\begin{tabular}{lcccccc}
\hline Demographic variable & \multicolumn{2}{c}{ Factor 1 } & \multicolumn{2}{c}{ Factor 2 } & \multicolumn{2}{c}{ Factor 3 } \\
\cline { 2 - 7 } & $\boldsymbol{r}$ & $\boldsymbol{p}$ & $\boldsymbol{r}$ & $\boldsymbol{p}$ & $\boldsymbol{r}$ & $\boldsymbol{p}$ \\
\hline Gender & -0.140 & $0.000^{*}$ & -0.146 & $0.000^{*}$ & -0.130 & $0.000^{*}$ \\
Age & 0.272 & $0.000^{*}$ & -0.026 & 0.135 & 0.013 & 0.447 \\
Education level & 0.234 & $0.000^{*}$ & 0.085 & $0.000^{*}$ & 0.089 & $0.000^{*}$ \\
Income level & 0.216 & $0.000^{*}$ & 0.260 & $0.000^{*}$ & 0.120 & $0.000^{*}$ \\
Marital status & 0.023 & 0.191 & -0.043 & $0.014^{* *}$ & -0.005 & 0.774 \\
Combined income & 0.225 & $0.003^{*}$ & 0.205 & $0.000^{*}$ & 0.117 & $0.000^{*}$ \\
Number of dependents & 0.052 & $0.003^{*}$ & 0.174 & $0.000^{*}$ & 0.014 & 0.422 \\
Value of assets & -0.020 & 0.256 & 0.213 & $0.000^{*}$ & 0.104 & $0.000^{*}$ \\
\hline
\end{tabular}

*, Significant at a $1 \%$ level; **, significant at a $5 \%$ level (two-sided).

significant relationships are evidence that the higher the investors' education level, income, combined income, number of dependents and value of assets, the more they are willing to tolerate a higher level of risk. Again, gender showed a negative correlation, which indicates that females take on a lower risk tolerance level than males. Furthermore, marital status showed a negative relationship. Married investors were given a numerical value of 1 and unmarried individuals a numerical value of 2. A negative relationship indicates that if an investor is married, there will be a negative relationship, indicating that married investors will take a higher risk tolerance than unmarried investors.

Factor 3: With regard to the demographic variables gender, education level, income, combined income and value of assets, the $p$-values were below $1 \%$, which is overwhelming evidence to reject the null hypothesis, implying there is a statistically significant relationship between the mentioned demographic variables and risk tolerance as per factor 3, which presents personal attitudes and feelings. The positive significant relationships are evidence that the higher the investors' education level, income, combined income and value of assets, the more they are willing to tolerate a higher level of risk. Gender again showed a negative correlation, indicating that females take on a lower risk tolerance level than males.

\section{Multi-regression analysis of risk tolerance of factor 1 and dependent variables}

Because of all the categorical demographic (dependent) variables, a multiple regression model was built. The financial risk tolerance score was compared with all the different variables to see what groups of variables had the highest relationship to the total risk tolerance score of factor 1 (level of risk). It was determined that factor 1 had a much larger effect than the other factors on how financial risk tolerance is determined. Factors 2 and 3 were, therefore, not focused on because of this significant finding.

A correlation analysis was done between the eight demographic variables (independent variables) to identify if any of the identified variables had an effect on another identified variable. If correlated variables are used together, it can lead to co-linearity that makes further analysis of the data inaccurate (Wegner 2007:418). Variables must maintain independent relations with other variables. As expected, 
TABLE 6: Multiple-regression models tested of factor 1 (level of risk).

\begin{tabular}{ccccl}
\hline Model & Adjusted $\boldsymbol{R}^{2}$ & $\boldsymbol{R}^{\mathbf{2}}$ & $\begin{array}{c}\text { No. of } \\
\text { variables }\end{array}$ & Variables \\
\hline 1 & 0.1370 & 0.1398 & 8 & $\begin{array}{l}\text { Gender; Baby Boomers; Generation X; } \\
\text { Millennials; Education level; Income level; } \\
\text { Marital status and Combined income }\end{array}$ \\
\hline 3 & 0.1369 & 0.1400 & 9 & $\begin{array}{l}\text { Gender; Baby Boomers; Generation X; } \\
\text { Millennials; Education level; Income } \\
\text { level; Marital status; Combined income } \\
\text { and Net asset value }\end{array}$ \\
\hline 4 & 0.1367 & 0.1398 & 9 & $\begin{array}{l}\text { Gender; Baby Boomers; Generation X; } \\
\text { Millennials; Education level; Income } \\
\text { level; Marital status; Combined income } \\
\text { and Number of dependants }\end{array}$ \\
& 0.1366 & 0.1401 & 10 & $\begin{array}{l}\text { Gender; Baby Boomers; Generation X; } \\
\text { Millennials; Education level; Income level; } \\
\text { Marital status; Combined income; Number } \\
\text { of dependants and Net asset value }\end{array}$ \\
\hline 5 & 0.1363 & 0.1388 & 7 & $\begin{array}{l}\text { Gender; Generation X; Millennials; } \\
\text { Education level; Income level and } \\
\text { Combined income }\end{array}$ \\
\hline
\end{tabular}

a high correlation (0.766) was found between income level and combined income level. Furthermore, the expectation was that as investors age, their net asset value will increase. A moderate negative correlation $(-0.515)$ between age and value of net assets was found. This is a strange phenomenon and age was in this section replaced by a related variable, namely generations, which included Baby Boomers, Generation X and Millennials.

Although a high correlation exists between income level and combined income level, the researchers decided, on the advice of the statistician, to run several multiple regression models, which test as many $x$ variables as possible. Table 6 illustrates the results of the five multiple regression models that had the highest adjusted $R^{2}$ values. The model (model 1) with the highest adjusted $R^{2}$ value, which best presented the data, was selected as the best model that consists of the demographic variables that had the highest effect on the financial risk tolerance score. In model 1, the adjusted $R^{2}$ implies that $13.70 \%$ of the financial risk tolerance scores can be explained by the research variables. The model is as follows:

$y=b_{0}+b_{1} x_{1}+b_{2} x_{2}+b_{3} x_{3}+\ldots+b_{8} x_{8}$

where

$y=$ estimated value of the dependend variable

$b_{0}=$ the $y$ intercept coefficient

$b_{1^{\prime} 2^{\prime} 3^{3}}, \ldots, b_{8}=$ the sample coefficients for the independent variable

$x_{1}=$ Gender $; x_{2}=$ Baby Boomers; $x_{3}=$ Generation, $x_{4}=$ Millennials; $x_{5}=$

Education level; $x_{6}=$ Income level; $x_{7}=$ Marital status; $x_{8}=$ Combined income

Note that model 1 excluded the demographic variables number of dependents and net asset value.

A further analysis was done on model 1 and the results are indicated in Table 7.

The parameter estimate in Table 7 is a descriptive measure of an entire sample and measures the change in the response associated with a one-unit change of the predictor. Standard error measures the accuracy of a predictor made with a
TABLE 7: Parameter estimates of model 1.

\begin{tabular}{lccccc}
\hline Variable & $\begin{array}{c}\text { Parameter } \\
\text { estimate }\end{array}$ & $\begin{array}{c}\text { Std. } \\
\text { error }\end{array}$ & $t$ & $p$ & $\begin{array}{c}\text { Squared semi-partial } \\
\text { correlation type II }\end{array}$ \\
\hline Gender & -0.22 & 0.04 & -5.09 & $0.000^{*}$ & 0.009 \\
Baby Boomers & 0.35 & 0.07 & 4.92 & $0.000^{*}$ & 0.008 \\
Generation X & 0.58 & 0.08 & 7.51 & $0.000^{*}$ & 0.020 \\
Millennials & 0.76 & 0.08 & 9.99 & $0.000^{*}$ & 0.035 \\
Education level & 0.17 & 0.02 & 7.07 & $0.000^{*}$ & 0.017 \\
Income level & 0.06 & 0.02 & 2.24 & $0.025^{* *}$ & 0.001 \\
Marital status & 0.11 & 0.06 & 1.72 & 0.086 & 0.001 \\
Combined income & 0.07 & 0.02 & 2.51 & $0.012^{* *}$ & 0.002 \\
\hline
\end{tabular}

*, Significant at a $1 \%$ level; $* *$, significant at a $5 \%$ level (two-sided).

regression line. A $t$-value finds a significant relationship between the population mean and a hypothesised value. The hypotheses were tested against the $p$-values and it is evident that gender, Baby Boomers, Generation X, Millennials and education level obtained a $p$-value of less than $1 \%$. Overwhelming evidence was, therefore, found to reject the null hypothesis regarding these five demographic variables. Furthermore, a $p$-value of less than $5 \%$ was found, and the null hypothesis rejected for income level and combined income, which suggests a strong relationship of these variables with the financial risk tolerance score of factor 1.

However, the most important value was the squared semipartial correlation type 11. A squared semi-partial correlation is calculated between a residual value and a raw variable (Gujarati \& Porter 2010). The squared semi-partial correlation indicated the proportion of the variance in $y$ (financial risk tolerance score) associated with one specific variable predictor, but not any of the other predictors. The closer the squared semi-partial correlation is to 1 , the higher the impact of the predictor variable on the financial risk tolerance score.

Based on the squared semi-partial correlation, Millennials (3.5\%) had the closest relationship to the financial risk tolerance score, with Generation X second (2\%) and education level third (1.7\%). From Table 7, the following was, to a lesser extent, related to investors' risk tolerance scores: gender, Baby Boomers, income level, marital status and combined income levels, which all had a score of less than $1 \%$.

\section{Discussion}

The secondary objective of the study was to analyse the 25-item FinaMetrica questionnaire into factors to refine the measurement of investors' risk tolerance. However, a corrected-item correlation analysis identified two items that should be eliminated from further analysis to determine risk tolerance scores because they correlate negatively and very low with all the other items, respectively. The exploratory factor analysis identified 16 items to be included in three factors: factor 1 (level of risk - 10 items), factor 2 (past experience -4 items) and factor 3 (personal feelings and attitudes -2 items). This exploratory analysis differs from Holzhauer et al.'s (2016) confirmative factor analysis that confirmed the validity of five predetermined structured factors. A communality estimate was also conducted to determine the importance of the items by how they correlate with the risk tolerance score. 
To reach the main objective of the study, the association between the financial risk tolerance scores per factor and the eight demographic variables was tested. The study found that the risk tolerance as per factors 1,2 and 3 shows the following: men are statistically significantly more risk tolerant than women, and investors' education level, income level and combined income are all positively statistically significantly associated with risk tolerance. These findings are supported by the studies of Hallahan et al. (2004), Grable et al. (2009), Faff et al. (2009), Yoa et al. (2011), Sulaiman (2012) and all four countries (South Africa, Australia, the United Kingdom and the United States) in Mabalane's study (2015). Metherell (2011) found that only less educated men are more risk tolerant than more educated women and that income level and education level are insignificantly associated.

Although the literature review indicated the logic that age and risk tolerance could be negatively correlated, the study found that risk tolerance as per factor 1 is significantly positively associated with age. Furthermore, it is found insignificantly associated regarding factors 2 and 3. Sulaiman (2012) also rejected his hypothesis and found a positive relationship. Studies such as Yoa et al. (2011), Metherell (2011) and Grable et al. (2016) found negative relationships, while Hallahan et al. (2004) and Faff et al. (2009) found nonsignificant relationships when the data were treated as linear, but significantly negatively related when treated as non-linear data. Mabalane (2015) also found insignificant relationships for South Africa, but significant negative relationships for Australia, the United Kingdom and the United States.

This study found that risk tolerance per factors 1 and 3 is not significantly associated with marital status. This is supported by the studies of Grable et al. (2016) and Mabalane (2015), who found similar results for South Africa, Australia, the United Kingdom and the United States. However, opposed to the studies of Hallahan et al. (2004), Faff et al. (2009) and Sulaiman (2012), our study found that married investors are more risk tolerant as per factor 2, past experience, than unmarried investors.

The study found that the number of dependents is significantly positively associated with risk tolerance, as measured by factors 1 and 2. This is opposite to what was found in the studies of Hallahan et al. (2004), Faff et al. (2009) and Mabalane (2015) for Australia, the United Kingdom and the United States, but not significant with regard to South Africa. Our study found that risk tolerance only measured by factor 3, personal attitudes and feelings, is non-significantly associated with the number of dependents, as supported by Grable et al. (2016). For total value of assets, our study only found a significant positive association between risk tolerance as per factors 2 and 3 and value of assets and insignificant relationships with regard to factor 1, where Mabalane (2015) found a significant association from the South African data between risk tolerance and value of assets.
A further analysis was conducted where multiple regression analysis has been applied. In this exercise, we built a model that best fits the data to determine the association between demographic variables and the risk tolerance as measured by factor 1 . In this exercise, age was replaced by three generations, Baby Boomers, Generation X and Millennials. All three generations' education, income and combined income levels are significantly positively related to risk tolerance, and males are significantly more risk tolerant than women. This analysis also revealed that marital status is insignificantly associated with risk tolerance. With large sample sizes, it is not unusual to easily find significant variables. Other researchers experienced a similar phenomenon. For example, Mabalane (2015) also calculated eta-squared values to better explain the strength of relationships, and studies such as Hallahan et al. (2004) and Faff et al. (2009) make use of non-linear analysis. In our study, the squared semi-partial correlation type II was calculated to better explain the relationships. Nevertheless, although statistically significant, individually, the demographic variables have little impact on risk tolerance.

\section{Conclusion}

Risk tolerance, an aspect of utility, for a sample of 3473 South African investors, was calculated and compared to their demographic variables. Many previous studies did similar investigations. However, breaking up the risk tolerance into factors contributes to a more refined analysis being conducted. Some unique findings were revealed from this study, that is, as investors age, their risk tolerance increases (as per factor 1); married investors are more risk tolerant than unmarried ones (as per factor 2); and the number of dependents is positively associated with risk tolerance factors 1 and 2 . What was learnt from the study is that we can now understand more precisely which aspects of risk tolerance as utility are associated, and the direction of the association, and not associated with the demographic variables.

The practical value of the study is that investors and financial advisors have a more enhanced view to better understand the degree of association, or the impact, of demographic variables on investors' level of risk; and the roles of past experiences and personal attitudes and feelings are associated with demographic variables.

The limitation of the study is that this study only analysed the data related to South African respondents. As indicated in the 'Discussion' section, it was clear that there are differences between the South Africans and other countries' results. Furthermore, this study did not analyse the relationship between the calculated risk tolerance score and the perception score of each individual investor. Future studies may address these limitations.

\section{Acknowledgements}

The authors thank FinaMetrica Pty Ltd for providing the data for this study and Albert Hong and Nicki Potts, PlanPlus Global Inc., who supported in this process. 
The authors also thank Prof. Faans Steyn, Statistical Consultation Services at the North-West University, for the advice and support.

\section{Competing interests}

The authors have declared that no competing interests exist.

\section{Authors' contributions}

The content of this article was extracted from the master's study of L.M., on whom the degree was conferred in 2019. M.O. was the supervisor for the master's study and drafted the article.

\section{Funding Information}

This research received no specific grant from any funding agency in the public, commercial or not-for-profit sectors.

\section{Data availability statement}

Data sharing is not applicable to this article as no new data were created or analysed in this study.

\section{Disclaimer}

The views and opinions expressed in this article are those of the authors and do not necessarily reflect the official policy or position of any affiliated agency of the authors.

\section{References}

Abhijeet, C. \& Dinesh, S., 2010, 'Investment management by individual investors A behavioral approach', Journal of Behavioural Finance 7, 7-18.

Bajtelsmit, V.L. \& Bernasek, A., 1996, 'Why do women invest differently than men?', Financial Counselling and Planning 7, 1-10. https://doi.org/10.2139/ssrn.2238

Bannier, C.E. \& Neubert, M., 2016, 'Gender differences in financial risk taking: The role of financial literacy and risk tolerance', Economic Letters 145, 130-135. https:// doi.org/10.1016/j.econlet.2016.05.033

Chavali, K. \& Mohanraj, M.P., 2016, 'Impact of demographic variables and risk tolerance on investment decisions: An empirical analysis', International Journal of Economics and Financial Issues 6, 169-175.

Cordell, D.M., 2001, 'RiskPACK: How to evaluate risk tolerance', Journal of Financial Planning 1, 36-40.

Costello, A.B. \& Osborne, J.W., 2005. 'Best practices in exploratory factor analysis: Four recommendations to getting the most from your analysis', Practica Assessment, Research \& Evaluation 10(7), 1-9.

Davis, J., Hands, W. \& Maki, U., 1997, 'Expected utility theory', Textbook of Economic Methodology 1(1), 342-350.

DeHart, W.B., Friedel, J.E., Lown, J.M. \& Odum, A.L., 2016, 'The effects of financial education on impulsive decision making' Financial Education and Decision Making 11(7), 1-16. https://doi.org/10.1371/journal.pone.0159561

Faff, R., Hallahan, T. \& McKenzie, M., 2009, 'Nonlinear linkages between financial risk tolerance and demographic characteristics', Applied Economics Letter 16, risk tolerance and demographic characteristics', Applied

FinaMetrica, 2015, Understanding risk tolerance, viewed 01 August 2018, from https://www.riskprofiling.com/News,-Blogs,-Newsletters,-Webinars/blog/May2015/understandingrt.

FinaMetrica, 2019, Website, viewed 22 February 2019, from https://www.riskprofiling com/How-it-Works.

Field, A., 2009, Discovering statistics using SPSS, 3rd edn., Sage, London.

Flom, P., 2018, National ETD Portal, viewed 01 May 2018, from https://sciencing.com/ calculate-item-total-correlation-coefficients-8726484.html.

Gilliam, J. \& Chatterjee, S., 2011, 'The influence of birth order on financial risk tolerance', Journal of Business \& Economic Research 9(4), 43-50. https://doi.org/ 10.19030/jber.v9i4.4208
Grable, J.E., 2000, 'Financial risk tolerance and additional factors that affect risk taking in everyday money matters', Journal of Business and Psychology 14(4), 625-630. https://doi.org/10.1023/A:1022994314982

Grable, J.E., 2013, 'Gender, wealth, and risk: Why are baby boomer women less risk tolerant than baby boomer men?', Journal of Financial Service Professionals 67(3), 7-9

Grable, J.E. \& Lytton, R.H., 2003, 'The development of a risk assessment instrument: A follow-up study', Financial Services Review 12, 257-274.

Grable, J.E., Heo, W. \& Kruger, M., 2016, 'The intertemporal persistence of risk tolerance scores', Journal of Financial Planning, August, 42-51.

Grable, J.E., McGill, S. \& Britt, S., 2009, 'Risk tolerance estimation bias: The age effect', Journal of Business and Economic Research 7(7), 1-7. https://doi.org/10.19030/ jber.v7i7.2308

Gujarati, D.N. \& Porter, D.C., 2010, Essentials of Econometrics, 4th edn., McGraw-Hill, Singapore.

Hallahan, T.A., Faff, R.W. \& McKenzie, M.D., 2004, 'An empirical investigation of personal financial risk tolerance', Financial Services Review 13, 57-78.

Heo, W., Grable, J.E. \& Rabbani, A.C., 2018, 'A test of the relevant association between utility theory and subjective risk tolerance: Introducing the profit-to-willingness ratio', Journal of Behavioral and Experimental Finance 19, 84-88. https://doi.org/ 10.1016/j.jbef.2018.05.003

Ho, K., Milevsky, M.A. \& Robinson, C., 1994, 'Asset allocation, life expectancy and shortfall', Financial Services Review 3(2), 109-126. https://doi.org/10.1016/10570810(94)90017-5

Holzhauer, H.M., Lu, X., McLeod, R. \& Wang, J., 2016, 'RiskTRACK: The five-factor model for measuring risk tolerance', The Journal of Risk Finance 17(4), 428-445. https://doi.org/10.1108/JRF-04-2016-0054

Kahneman, D. \& Tversky, A., 1979, 'Prospect theory: An analysis of decision unde risk', Econometrica 47, 263-292. https://doi.org/10.2307/1914185

Kannadhasan, M., 2015, 'Retail investors' financial risk tolerance and their risktaking behavior: The role of demographics as differentiating and classifying factors', IIMB Management Review 27, 175-184. https://doi.org/10.1016/j. iimb.2015.06.004

Kuzníak, S., Rabbani, A., Heo, W., Ruiz-Menjivar, J. \& Grable, J.E., 2015, 'The Grable and Lytton risk-tolerance scale: A 15-year retrospective', Financial Services Review 24, 177-192.

Lucarelli, C, Uberti, P. \& Brighetti, G., 2014, 'Misclassification in financial risk tolerance', Journal of Risk Research 18(4), 467-482. https://doi.org/10.1080/13669877. 2014.910678

Mabalane, M.D., 2015, 'Cultural and demographic differences in financial risk tolerance', Dissertation for the fulfilment of the MCom degree, University of Pretoria.

Metherell, C., 2011, 'The impact of demographic factors on subjective financial risk tolerance: A South African study', Thesis for the fulfilment of the MCom degree, University of Kwazulu-Natal.

Moreschi, R.W., 2005, 'An analysis of the ability of individuals to predict their own risk tolerance', Journal of Business \& Economic Research 3(2), 39-48. https://doi. org/10.19030/jber.v3i2.2744

Paradi, J.C., Sherman, H.D. \& Tam, F.K. (eds.), 2018, 'Financial services beyond banking: Risk tolerance measures for portfolio investors', Data envelopment analysis in the financial services industry, pp. 313-325, Springer, Cham.

Pan, C.H. \& Statman, M., 2012, 'Questionnaires risk tolerance, regret, overconfidence, and other investor propensities', The Journal of Investment Consulting 13(1) 54-63. https://doi.org/10.2139/ssrn.1549912

Pietersen, J. \& Maree, K., 2016, 'Standardisation of a questionnaire', in K. Maree (ed.), First steps in research, 2nd edn., pp. 238-249, Van Schaik Publishers, Pretoria.

Roszkowski, M.J. \& Grable, J., 2005, 'Estimating risk tolerance: The degree of accuracy and the paramorphic representations of the estimate', Association of Financial Counseling and Planning Education 16(2), 29-46.

Russo, J.E. \& Schoemaker, P.J.H., 1992, 'Managing overconfidence', Sloan Management Review 33(2), 7-17.

Ryack, K.N. \& Sheikh, A., 2016, 'The relationship between time perspective and financial risk tolerance in young adults', Financial Services Review 25, 157-180.

Serafino, J., 2018, National ETD Portal, viewed 18 March 2018, from www.mentalfloss. com.

Sulaiman, E.K., 2012, 'An empirical analysis of the financial risk tolerance and demographic features of individual investors', Procedia Economics and Finance 2 109-115. https://doi.org/10.1016/S2212-5671(12)00070-6

Van de Venter, G., Michayluk, D. \& Davey, G., 2012, 'The longitudinal study of financial risk tolerance', Journal of Economic Psychology 33, 794-800. https://doi.org/ 10.1016/j.joep.2012.03.001

Wegner, T., 2007, Applied business statistics: Methods and Excel-based applications, Juta, Cape Town.

Yoa, R., Sharpe, D.L. \& Wang, F., 2011, 'Decomposing the age effect on risk tolerance', The Journal of Socio-Economics 40, 879-887. https://doi.org/10.1016/j. socec.2011.08.023

Yook, K.C. \& Everett, R., 2003, 'Assessing risk tolerance: Questioning the questionnaire method', Journal of Financial Planning 16(8), 48-54. 


\section{Appendix 1}

TABLE 1-A1: Demographic variables

\begin{tabular}{|c|c|}
\hline Variable & Measurement \\
\hline Gender & $1=$ Male; 2 = Female \\
\hline Year of birth & Year of birth entered \\
\hline Education level & 1 = Did not complete high school; 2 = Completed high school; $3=$ Trade or diploma qualification; $4=$ University degree or higher qualification \\
\hline Income level & $\begin{array}{l}1=\text { Under R100 } 000 \text { p.a.; } 2 \text { = R100 } 000 \text { - R249 } 999 \text { p.a.; } 3 \text { = R250 } 000 \text { - R499 } 999 \text { p.a.; } 4 \text { = R500 } 000 \text { - R999 } 999 \text { p.a.; } 5 \text { = R1 } 000000 \text { - R2 } 999999 \text { p.a.; } \\
\text { 6= R3 } 000000 \text { and above }\end{array}$ \\
\hline Marital status & $1=$ Yes; 2 = No \\
\hline $\begin{array}{l}\text { Annual combined } \\
\text { income if married }\end{array}$ & $\begin{array}{l}1=\text { Under R100 } 000 \text { p.a.; } 2 \text { = R100 } 000 \text { - R249 } 999 \text { p.a.; } 3 \text { = R250 } 000 \text { - R499 } 999 \text { p.a.; } 4 \text { = R500 } 000 \text { - R999 } 999 \text { p.a.; } 5 \text { = R1 } 000000 \text { - R2 } 999999 \text { p.a.; } \\
6 \text { = R3 } 000000 \text { and above }\end{array}$ \\
\hline Number of dependents & Total number of dependents beside yourself to be entered \\
\hline Value of net assets & $\begin{array}{l}1=\text { Under R50 000; } 2=R 50000-R 124999 ; 3=R 125000-R 249 \text { 999; } 4=R 250000-R 499999 ; 5=R 500000-R 999999 ; 6=R 1000000-R 2499999 ; \\
7=R 2500000-R 4999999 ; 8=R 5000000-R 9999999 ; 9=R 10000000-R 24999999 ; 10=25000000 \text { and above }\end{array}$ \\
\hline
\end{tabular}

Source: FinaMetrica, 2015, Understanding risk tolerance, viewed 01 August 2018, from https://www.riskprofiling.com/News,-Blogs,-Newsletters,-Webinars/blog/May-2015/understandingrt 


\section{Appendix 2}

\section{Summary of FinaMetrica's 25-items questionnaire}

1. You have to rate your willingness to take financial risk.

2. You have to state how easily you adapt when things go wrong financially.

3. When you think of the word 'risk' in a financial context, which of the words comes to mind first: Danger; Uncertainty; Opportunity of Thrill.

4. Have you ever invested a large sum in a risky investment mainly for the 'thrill' of seeing whether it went up or down in value?

5. If you had to choose between more job security with a small pay increase and less job security with a big pay increase, which would you pick?

6. When faced with a major financial decision, are you more concerned about possible losses or possible gains?

7. How do you feel about financial decisions after making them?

8. If you were in a job where you could choose to be paid a salary, commission or a mix of both. What would you pick?

9. What degree of risk would you have taken with your financial decisions in the past?

10. What degree of risk are you currently prepared to take with your financial decision?

11. Have you ever borrowed money to make an investment (other than for a home)?

12. How much confidence do you have in your abilities to make good financial decisions?

13. Suppose that 5 years ago you bought stock in a highly regarded company. The same year the company experienced a severe decline in sales because of poor management. The price of the stock dropped drastically and you sold at a substantial loss. The company has been restricted under new management, and most experts now expect it to produce better than average returns. Given your bad past experience with the company, would you buy stock now?

14. Investments can go up and down in value, and experts often say you should be prepared to weather the downturn. By how much could the total value of all your investments go down before you would begin to feel uncomfortable?

15. Assume that a long-lost relative dies and you inherit a house which is in a poor condition but is located in a suburb that is becoming popular. As is, the house would probably sell for R3 000 000, but if you were to spend about R1 000000 in renovations, the selling price would be around R6 000000 . However, there is some talk of construction a major highway next to the house, and this would lower its value considerably. What would you do?

16. Most investment portfolios have a mix of investments - some of the investments may have high expected returns but with high risk, some may have medium expected returns and medium risk, and some may have low risk/ low return. (For example, stocks and real estate would be high-risk/high-return whereas cash and CDs (certificates of deposit) would be low-risk/low-return.) Which mix of investments do you find most appealing? Would you prefer all low-risk/low-return, all high-risk/high-return, or somewhere in between?

17. You are considering placing one-quarter of your investment funds into a single investment. This investment is expected to earn about twice the $C D$ (certificate of deposit) rate. However, unlike CD, this investment is not protected against loss of the money invested. How low would the chance of a loss have to be for you to make the investment?

18. With some types of investment, such as cash and CDs (certificate of deposit), the value of the investment is fixed. However, inflation will cause the purchasing power of thus value to decrease. With other types of investments, such as stocks and real estate, the value is not fixed. It will vary. In the short term it may even fall below the purchase price. However, over the long term, the value of the stocks and real estate would certainly increase by more than the rate of inflation. With this in mind, which is more important to you - that the value of your investment does not fall or that it retains its purchasing lower?

19. In recent years, how have your personal investments changed?

20. When making investments, risk and return usually go hand-in-hand. Investments which produce above average returns are usually above average risk. With this in mind, how much of the funds you have available to invest would you be willing to place in investments where both return and risk are expected to be above average?

21. Think of the average rate of return you would expect to earn on an investment portfolio over the next 10 years. How does this compare with what you think you would earn if you invested the money in 1-year CDs (certificates of deposit)?

22. People often arrange their financial affairs to qualify for a government benefit or obtain a tax advantage. However, a change in legislation can leave them worse off than if they had done nothing. With this in mind, would you take a risk in arranging your affairs to qualify for a government benefit or obtain a tax advantage?

23. Imagine that you are borrowing a large sum of money at some time in the future. It is not clear which way interest rates are going to move - they might go up, they might go down, no one seems to know. You could take a variable interest rate that will rise and fall as the market rate changes. Or you could take a fixed interest rate which is $1 \%$ more than the current variable rate but which will not change as the market rate changes. Or you could take a mix of both. How would you prefer your loan to be made up?

24. Insurance can cover a wide variety of life's major risks - theft, accident, illness, death, etc. How much coverage do you have?

25. This questionnaire is scored on a scale of $0-100$. When the scores are graphed they will follow the familiar bell-curve of the normal distribution. The average score is 50. Two-thirds of all scores are within 10 points of the average. Only 1 in 1000 is less than 20 or more than 80 . What do you think your score will be? 